\title{
A Bacillus thuringiensis $\delta$-endotoxin induces programmed cell death in mosquito larvae
}

\author{
David Smouse $^{1,2}$ and James Nishiura ${ }^{1}$ \\ 1 Department of Biology, Brooklyn College and the City University of New York, \\ Brooklyn, NY, 11210, USA \\ 2 corresponding author: David Smouse. tel: 718951 5728; fax: 718951 5728; \\ email: jtnbc@cunyvm.cuny.edu
}

Received: 5.9.96; revised: 11.2.97; accepted 16.5.97

Edited by C.J. Thiele

\begin{abstract}
We present evidence that a $\delta$-endotoxin isolated from Bacillus thuringiensis subsp.israelensis induces programmed cell death in polytene midgut cells of Culex pipiens larvae. After exposure to toxin, polytene nuclei in the anterior region of the larval midgut undergo many of the morphological and physiological changes which are characteristic of apoptosis, including the ability to stain with the vital dye, acridine orange, and fragmentation of nuclear DNA as demonstrated by agarose gel electrophoresis and in situ TUNEL labeling. The temporal sequence of toxin ingestion, acridine orange staining and larval death suggests a cause and effect relationship between programmed cell death and larval death. Amino sugars that interfere with toxicity also interfere with the time course of acridine orange staining of larval polytene nuclei. The toxin first causes programmed cell death of anterior midgut and gastric caeca cells and, subsequently, posterior midgut cells. This pattern is similar to the temporal sequence of larval polytene cell death that occurs during metamorphosis. From the size and distribution of the nuclei that are stained with acridine orange, it appears that only polytene midgut cells are affected by toxin and that the diploid regenerative cell are not affected.
\end{abstract}

Keywords: apoptosis; thuringiensis; mosquito; endotoxin

Abbreviations: Bti: Bacillus thuringiensis subsp. israelensis; $A O$, acridine orange, TDT, terminal deoxytransferase; dUTP, deoxygenin-labeled triphosphate; gluNAc, N-acetylglucosamine; ICE, interleukin- $\beta$ converting enzyme; DTT, dithiothrietol; MMIM, Mitsuhashi and Maramonosch insect medium

\section{Introduction}

The programmed death of vertebrate cells has profound significance in a variety of normal and pathological processes. (Wyllie et al, 1980; Ellis et al, 1991; Raff, 1992; Thompson, 1995). In addition, it has recently been found to be an important mechanism for the elimination of cells during normal insect development (Schwartz et al, 1990; Robinow et al, 1993; Zakeri and Lockshin, 1994; Steller, 1995). In this report we present evidence that programmed cell death is also involved in pathological processes in insects. We show that the $\delta$-endotoxin, synthesized by Bacillus thuringiensis subsp. israelensis (Bti), induces apoptosis, or programmed cell death, in the larval midgut cells of the mosquito, Culex pipiens.

The $\delta$-endotoxins are highly specific insecticidal protein toxins encoded by the plasmid-borne Cry genes of the soil bacterium $B$. thuringiensis. They are synthesized by sporulating cells as large precursor proteins that form parasporal crystalline inclusions. Upon ingestion by susceptible species of insects the prototoxins are solubilized and digested by gut proteases to yield the insecticidal polypeptides. Different strains, or subspecies, of $B$. thuringiensis synthesize toxins with relatively narrow target specificities. Some strains produce toxins lethal only to Coleopteran, Dipteran, or Lepidopteran larvae, while others produce toxins lethal to species from more than one order. The $\delta$-endotoxins also display differences in relative toxicity towards different target species within an order (for reviews see Höfte and Whitely, 1989; Gill et al, 1992; Tabashnik, 1994).

The specificity of the $\delta$-endotoxins has been postulated to be partly due to solubilization and proteolytic activation of toxin proteins in the insect midgut (Haider et al, 1986; Oppert et al, 1994), and to the presence of specific toxin receptors on the brush border membranes of midgut cells. Saturable, high-affinity binding sites for $\delta$-endotoxins have been described for some insect species (Hofmann et al, 1988a, b; van Rie et al, 1989; Knight et al, 1994, 1995; Curtiss et al, 1995; Gill et al, 1995; Vadlamudi et al, 1995; Villa et al, 1995), and there is evidence that such binding initiates the toxins' lethal effects (van Rie et al, 1990; Ferré et al, 1991; Maclntosh et al, 1991; Sanchis et al, 1994; Masson et al, 1995a, b).

Despite extensive commercial use for nearly 30 years, the mechanisms by which the $\delta$-endotoxins exert their insecticidal effects are poorly understood. It has been shown that they bind with high affinity to receptors on the brush border membranes of larval midgut cells, and that this binding initiates a number of physiological changes in these cells. Lepidopteran-specific $\delta$-endotoxins have been reported to induce the formation of pores in brush border membrane vesicles (Knowles and Ellar, 1984; von Tersch et al, 1994), and to alter the transport of ions and amino acids across cell membranes (Sacchi et al. 1986; Villa et al, 1995). However, the relationships between the events occurring after toxin binding, the cellular mechanisms leading to changes in midgut cell membranes, and their contributions to the death of larvae following toxin ingestion, are still poorly understood. 


\section{Results}

\section{Acridine orange staining of larval midgut polytene cells in response to delta toxin}

The target tissue for the Bti $\delta$-endotoxin is the larval midgut epithelium (de Barjac, 1978; Charles and de Barjac, 1983), which is composed of large, highly polytene cells and smaller, diploid precursors of the adult midgut epithelium. Late thirdearly fourth instar Culex pipiens larvae were intoxicated by feeding them a particulate form of the $150 \mathrm{kDa}$ prototoxin at a concentration of $7.7 \mu \mathrm{g} / \mathrm{ml}$. They cleared the toxin from the media in about $30 \mathrm{~min}$. During the first $20 \mathrm{~min}$ of exposure the larvae displayed their characteristic swimming-feeding pattern (Clements, 1992). Between 20 and $30 \mathrm{~min}$ of toxin exposure, the larvae stopped swimming, sank to the bottom of the container, became immobile and unresponsive to tactile perturbation and were assumed dead. In order to determine if apoptosis was initiated in the midgut cells of toxin treated larvae we used the vital dye acridine orange (AO), a fluorescent, DNA-binding dye normally excluded from live cells but not from cells undergoing programmed cell death (Abrams et al, 1993). Neither the diploid nor the polytene midgut cells of larvae not exposed to toxin were stained with AO. After ten minutes of exposure to toxin no AO staining of midgut polytene nuclei was detected (Figure 1A). Within 20 to $30 \mathrm{~min}$ of exposure to toxin, the large, polytene nuclei of the anterior midgut stained intensely with $\mathrm{AO}$, indicating that these cells were undergoing programmed cell death (Figure $1 \mathrm{~B}$ and $\mathrm{C})$. Hoechst dye staining showed that the chromatin of midgut polytene nuclei from untreated larvae appeared homogeneous and uniformly distributed (Figure 1D). Thirty minutes after toxin exposure, Hoechst staining showed that the chromatin became granular, condensed and unevenly distributed (Figure 1E). Similar chromatin morphology was observed when toxin treated guts were stained with $A O$ (Figure $1 \mathrm{~F}$ ). The $\mathrm{AO}$ staining and chromatin condensation that occurred in midgut polytene nuclei subsequent to toxin exposure suggests that the toxin initiates an apoptotic response in these cells.

The morphology of the midgut cells also changed after larvae were exposed to toxin. Within $1 \mathrm{~h}$ of exposure to $7.7 \mu \mathrm{g} / \mathrm{ml}$ toxin the usual tight cell to cell contacts of the midgut epithelium were disrupted by large, intercellular spaces. The cells became irregular in shape and the gut, normally sturdy and easy to dissect, became fragile and easily dissociated. However, the vital dye trypan blue, which is an indicator of cell membrane integrity, did not stain midgut cells until $2 \mathrm{~h}$ after exposure to toxin,
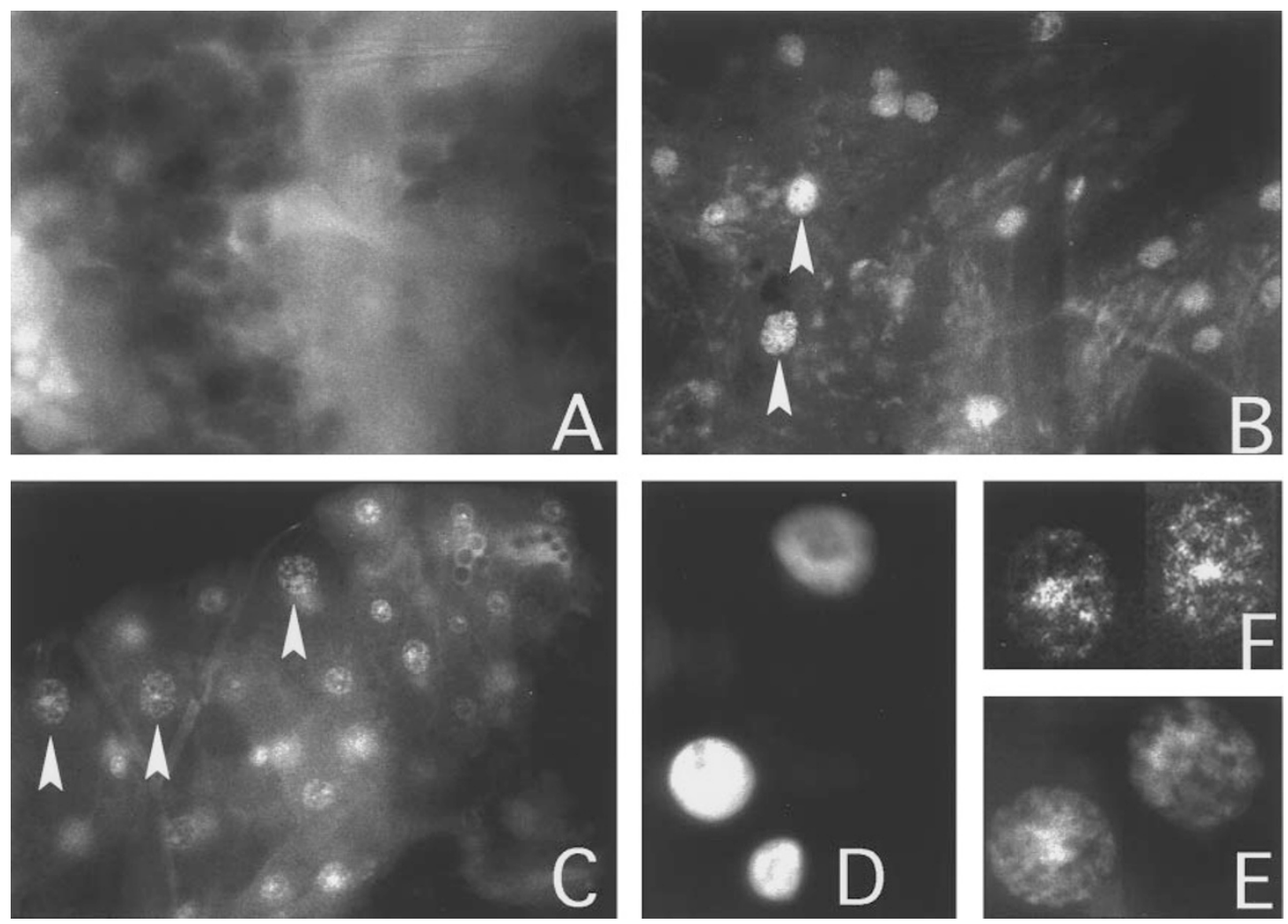

Figure 1 Acridine orange staining of larval midgut polytene cells induced by $\delta$-endotoxin. Panels $\mathbf{A}-\mathbf{E}$ are micrographs of third-fourth instar larval midguts stained with acridine orange (AO) or Hoechst dye to reveal the nuclei of apoptotic cells. In panels A-C the magnification is approximately 200 -fold. Midgut epithelia are from larvae exposed to $7.7 \mu \mathrm{g} / \mathrm{ml}$ particulate prototoxin for $10 \mathrm{~min}(\mathbf{A}), 20 \mathrm{~min}(\mathbf{B})$ and $30 \mathrm{~min}(\mathbf{C})$, prior to dissection and $\mathrm{AO}$ staining. Higher magnification photograph of Hoechst stained anterior midgut polytene nuclei from larvae not exposed to toxin (D). Higher magnification photograph of Hoechst stained anterior midgut polytene nuclei from larvae exposed to $7.7 \mu \mathrm{g} / \mathrm{ml}$ toxin for $30 \mathrm{~min}$ prior to dissection (E). Higher magnification photograph of $A O$ stained anterior midgut nuclei from larvae exposed to toxin for $30 \mathrm{~min}(\mathbf{F})$. The arrows in panels $\mathbf{B}$ and $\mathbf{C}$ point to the fluorescent, $\mathbf{A O}$ stained polytene nuclei of the anterior midgut cells. Similar fluorescent nuclei are absent from midguts in panel $\mathbf{A}$. 
indicating that gross changes in the plasma membrane occurred long after the onset of cell death. These results further indicate that $\delta$-endotoxin induces programmed death of mosquito midgut polytene cells, and that this cell death is morphologically similar to apoptosis observed in other organisms.

\section{DNA laddering and TUNEL labeling of midgut polytene cells in response to delta toxin}

Fragmentation of nuclear DNA into nucleosomal multimers is another characteristic feature of apoptosis (Eastman, 1995). To determine if DNA fragmentation occurred after toxin exposure, DNA was extracted from guts of untreated larvae and from guts of larvae exposed to toxin for $2 \mathrm{~h}$. Toxin treated cohorts were dissected and stained with $A O$ to confirm cell death occurred. DNA from guts of toxin treated larvae exhibited a ladder of low molecular weight DNA fragments corresponding to nucleosomal multimers that is characteristic of cells undergoing apoptosis (Figure 2) while similar ladders were either absent or very faintly observed in DNA from guts of untreated larvae.

DNA fragmentation was also detected, in situ, by labeling newly generated $3^{\prime}$-hydroxyl ends using terminal deoxytransferase (TDT) and digoxygenin-labeled deoxyuridine triphosphate (dUTP) (TUNEL-labeling, Gravieli et al, 1992). Midguts from larvae not exposed to toxin did not show any TUNEL labeling (Figure $3 \mathrm{~A}$ and D). Within $2 \mathrm{~h}$ of exposure to $3.8 \mu \mathrm{g} / \mathrm{ml}$ toxin, TUNEL labeling of polytene nuclei was detected in both the anterior and posterior midguts (Figure $3 \mathrm{~B}$ and $\mathrm{E}$ ) indicating that programmed cell death occurred. Hoechst staining of midguts from larvae exposed to toxin showed that there were more nuclei in both the anterior and posterior regions than were TUNEL labeled. In addition, there are many more nuclei in the posterior region of the midgut than there are in the anterior region (Figure $3 \mathrm{C}$ and F). Thus, by the criteria of $A O$ staining, cell morphology and DNA fragmentation it appears that the Bti $\delta$-endotoxin induces programmed death in larval midgut polytene cells.

\section{Toxin induced Acridine Orange staining is correlated with larval death}

To determine the relationship between toxin ingestion, $\mathrm{AO}$ staining and larval death, larvae were fed biotinylated prototoxin (b-prototoxin). After ingestion, and while in the endoperitrophic space (the area within the peritrophic membrane), the prototoxin is proteolytically cleaved into fragments of approximately $35-50 \mathrm{kDa}$, which are the presumed active forms of the toxin. These fragments pass, in turn, from the endoperitrophic space through the peritrophic membrane and into the ectoperitrophic space (the area between the peritrophic membrane and the gut epithelia and including the epithelia). At $10 \mathrm{~min}$ intervals following exposure to biotinylated prototoxin, larval midguts were dissected and the material within the endoperitrophic space was separated from the ectoperitrophic space by removal of the peritrophic membrane. As shown in Figure $4 \mathrm{~A}$, within $10 \mathrm{~min}$ of exposure to prototoxin, $35-50 \mathrm{kDa}$ toxin fragments could be detected in the ectoperitrophic

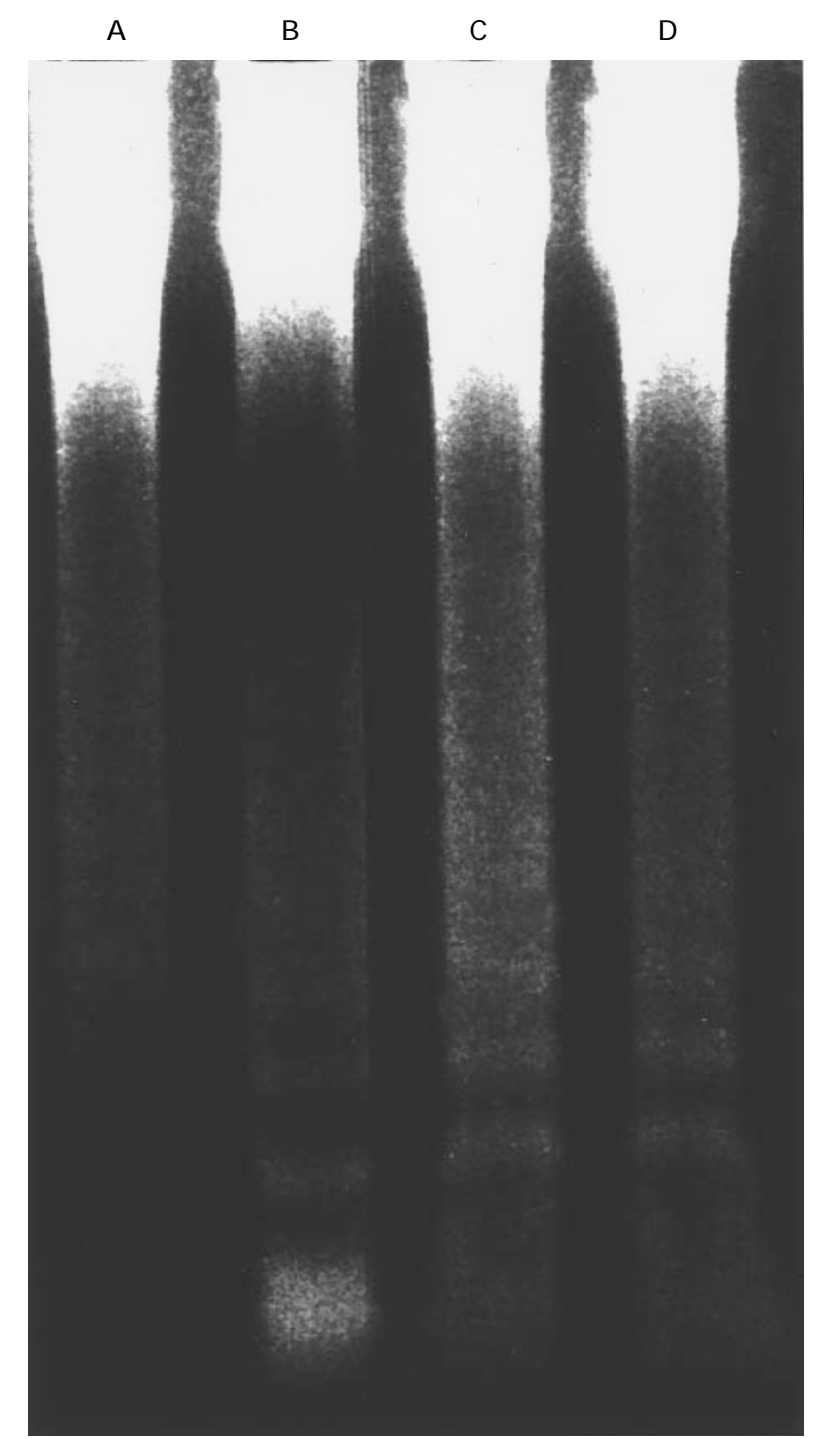

Figure 2 Nucleosomal DNA laddering induced by $\delta$-endotoxin. DNA was extracted from the isolated guts of 30 larvae not exposed to toxin (lane $\mathbf{A})$, and from the guts of 10 (lane B), 20 (lane C), and 30 (lane D) larvae exposed to $3.8 \mu \mathrm{g} / \mathrm{ml}$ toxin for $2 \mathrm{~h}$. The purified DNA was resolved on $2 \%$ agarose gels.

space, but there was no detectable $\mathrm{AO}$ staining of midgut nuclei (Figure $1 \mathrm{~A}$ ) and no larval death. Following $20 \mathrm{~min}$ exposure to prototoxin (Figure 4A), the relative amounts of the toxin fragments in the ectoperitrophic space increased, AO staining of midgut polytene nuclei was detectable (Figure 1B) but there was very little larval death. At $30 \mathrm{~min}$ of exposure to biotinylated prototoxin (Figure 4A), proteolytic fragments were detected in the ectoperitrophic space, there was intense AO staining of anterior midgut polytene nuclei (Figure 1C) and almost all of the larvae had died. These results demonstrate that the appearance of toxin in the ectoperitrophic space preceded AO staining of polytene nuclei, which in turn preceded larval death, and suggests a causal relationship between toxin ingestion, programmed cell death and larval death. 


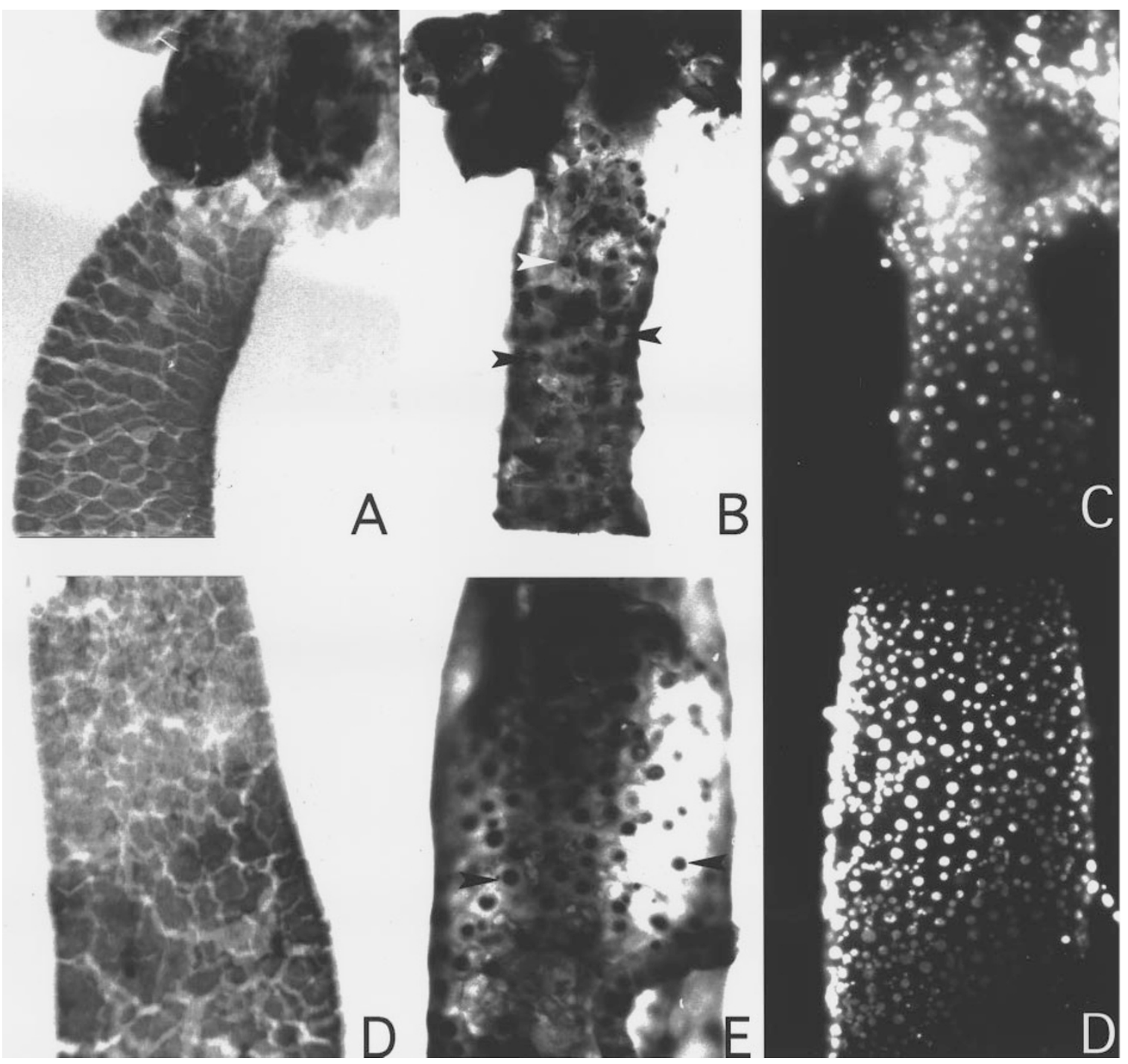

Figure 3 DNA fragmentation in larval midgut cells induced by $\delta$-endotoxin. Midguts dissected from control larvae and from larvae exposed to toxin were fixed and stained either with exogenously added TDT and digoxygenin-labeled dUTP (TUNEL labeled), or with Hoechst, as described in the Materials and Methods. Anterior (A) and posterior (D) midgut of larva not exposed to toxin and TUNEL labeled. Anterior (B) and posterior (E) midgut of larva exposed to $3.8 \mu \mathrm{g} / \mathrm{ml}$ toxin for $2 \mathrm{~h}$ and TUNEL labeled. Anterior (C) and posterior (F) midgut of larva exposed to $3.8 \mu \mathrm{g} / \mathrm{ml}$ toxin for $2 \mathrm{~h}$ and Hoechst stained.

The relationships between toxin dose, the time required to kill $50 \%$ of the larvae $\left(\mathrm{LT}_{50}\right)$ and $\mathrm{AO}$ staining of midgut polytene cells are shown in Table 1 . As the dose of toxin was reduced, the $\mathrm{LT}_{50}$ increased, as did the time between toxin exposure and $\mathrm{AO}$ staining of midgut polytene cells. However, regardless of the dose of toxin used, or the time required for the larvae to die, all of the dead larvae showed AO staining of anterior midgut polytene nuclei. At lower doses of toxin, the anterior midgut polytene nuclei of living larvae showed variable AO staining. Irrespective of toxin concentration and the time of onset of $A O$ staining, cell death was initiated in the anterior midgut region, $A O$ staining was transient, and the morphological changes associated with cell death still occurred, but may have been delayed by several hours.

Toxin-induced AO staining was highly restricted along the anterior-posterior axis of the midgut. While all of the anterior midgut cells were $\mathrm{AO}$-stained after $30 \mathrm{~min}$ exposure to $7.7 \mu \mathrm{g} / \mathrm{ml}$ toxin, none of the posterior midgut cells were stained (Figure 5B). The restriction of $\mathrm{AO}$ staining to the anterior midgut was not merely due to the transit time for toxin in the midgut, as experiments with biotinylated toxin, as well as with marked food particles, indicated that ingested food was rapidly transported through the midgut. A 40-fold range in toxin concentration (from $15 \mu \mathrm{g} / \mathrm{ml}$ to $0.38 \mu \mathrm{g} / \mathrm{ml}$ ) did not alter the restriction of AO staining to cells of the anterior midgut and gastric caeca. While cells of the posterior midgut eventually underwent programmed cell death (as indicated by TUNEL labeling), they did so much later than cells of the anterior midgut, and they never stained with $\mathrm{AO}$. The smaller diploid precursors of the adult midgut epithelium which are found intermixed with polytene cells in both anterior and posterior midguts did not stain with $\mathrm{AO}$ and did not die following 
exposure to toxin. The reason for the restriction in $A O$ staining to the anterior midgut cells is unclear. However the posterior and anterior midgut cells do differ with respect to embryological origin, cell density, morphology, and physiology (Richins, 1945; O'Brien, 1965, 1966). Interestingly, anterior midgut cells are also the first gut cells to initiate programmed cell death during metamorphosis (data not shown). The ability of midgut nuclei to stain with $\mathrm{AO}$ was temporally restricted as well, since the intensity and the number of nuclei stained first increased within $30 \mathrm{~min}$ of exposure, and subsequently declined within $1 \mathrm{~h}$ of exposure. The reason for the transient nature of the AO staining is unclear, although staining with Hoechst revealed that nuclei were still present despite the loss of $A O$ staining. Similar transient staining with $\mathrm{AO}$ has been observed in Drosophila polytene salivary gland cells undergoing programmed cell death (data not shown).

The ability of the $\delta$-toxin to induce programmed cell death in midgut cells was not restricted to third and fourth instar larvae. Second instar larvae were more sensitive to toxin

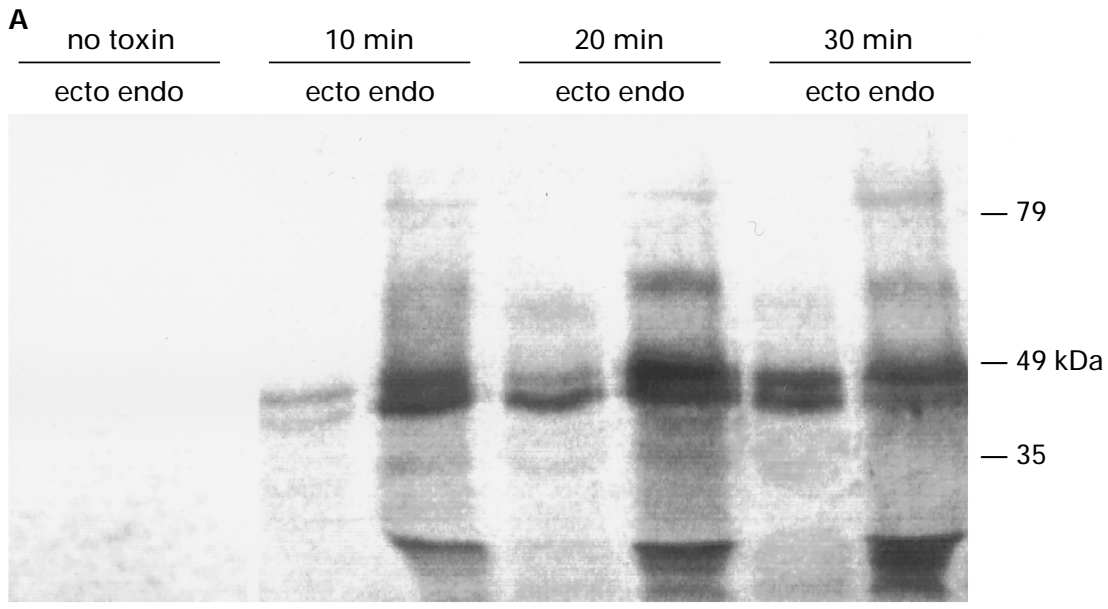

B

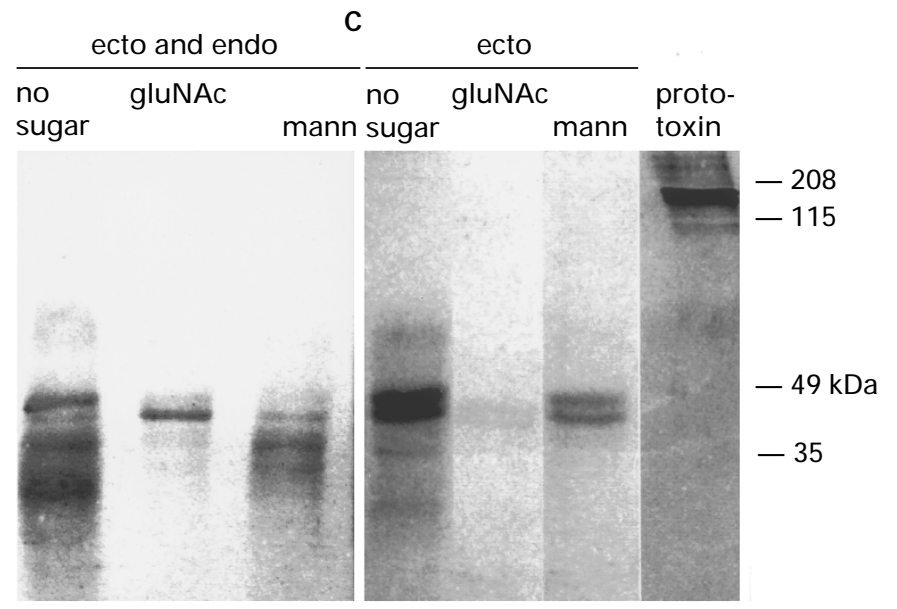

Figure 4 Programmed cell death requires correct processing and transport of $\delta$-endotoxin. (A) Time course of ingestion and processing of prototoxin. Larvae were fed biotinylated prototoxin for the time periods indicated. After toxin exposure, the guts were dissected and the peritrophic membranes separated from the gut epithelia. Each pair of lanes shows the pattern of biotinylated toxin fragments solubilized from the endoperitrophic space (endo) or the ectoperitrophic space (ecto). The endoperitrophic space contains the material bounded by the peritrophic membrane. The ectoperitrophic space contains the material between the peritrophic membrane and the gut epithelium and includes the epithelial cells. The apical regions of the gut epithelial cells are directly exposed to the material in the ectoperitrophic space. Effect of sugars on ingestion and processing of prototoxin. (B) Larvae were pretreated with no sugar, or $\mathrm{N}$-acetylglucosamine (gluNAc) or alpha methyl mannose (mann), as indicated in the Materials and Methods, and subsequently exposed to $7.7 \mu \mathrm{g} / \mathrm{ml}$ biotinylated prototoxin for $30 \mathrm{~min}$. After toxin exposure, proteins were solubilized from intact midguts (ecto and endo) and resolved on SDS gels. (C) Larvae were pretreated with no sugar, or Nacetylglucosamine (gluNAc) or mannose (mann) as indicated in the Materials and Methods and subsequently exposed to $7.7 \mu \mathrm{g} / \mathrm{ml}$ biotinylated prototoxin for $30 \mathrm{~min}$. After toxin exposure, the guts were dissected, the peritrophic membranes removed and the proteins in the ectoperitrophic space and epithelia (ecto) were solubilized and resolved in SDS gels. The undigested, biotinylated prototoxin is shown in Figure 3C. In each experiment the dissected gut material was placed directly into $50 \mu \mathrm{l}$ of $2 \times$ SDS/PAGE buffer and boiled for $2 \mathrm{~min}$ prior to electrophoresis. Twenty $\mathrm{ml}$ of each lysate were electrophoresed using $7.5 \%$ polyacylamide/ SDS gels and electroblotted onto nitrocellulose membranes which were probed with alkaline phosphotase-conjugated avidin. 
than were fourth instar larvae (Table 1) and, as seen with older larvae, AO staining was restricted to anterior midgut polytene nuclei. To eliminate the possibility that it was the induction of larval death, from any cause, which induced programmed cell death in midgut cells, larvae were exposed to anoxic conditions by overlaying the media with mineral oil. Larvae stopped swimming, sank to the bottom of the container and failed to respond to physical perturbation after approximately $1 \mathrm{~h}$. Midguts from hypoxia-induced dead larvae did not stain with AO (Figure 5D), indicating that death induced by other methods does not necessarily result in programmed cell death of larval midgut cells.
Programmed cell death was induced in isolated guts by exposure to toxin that was predigested, in vitro, with trypsin. Since the peritrophic membrane was removed from the isolated guts, in vitro trypsin digestion was necessary to activate the $150 \mathrm{kDa}$ prototoxin. In vivo, prototoxin activation is carried out by endoperitrophic proteases. In the absence of toxin, larval midguts placed in Mitsuhashi and Maramonosch culture medium continued to contract and twitch for up to $2 \mathrm{~h}$ after dissection. However, if treated with $14 \mu \mathrm{g} / \mathrm{ml}$ trypsin-digested toxin, the guts stopped twitching after approximately $30 \mathrm{~min}$, and the anterior midgut nuclei of the treated guts stained with

Table 1 Effect of toxin concentration on $\mathrm{LT}_{50}$ and $\mathrm{AO}$ staining

\begin{tabular}{|c|c|c|c|c|}
\hline $\begin{array}{l}\text { Toxin treatment } \\
(\mu \mathrm{g} / \mathrm{ml})\end{array}$ & $\begin{array}{c}\mathrm{LT}_{50} \\
\text { 4th instar } \\
\text { larvae } \\
\text { (minutes) }\end{array}$ & $\begin{array}{l}\text { Percent of guts from dead } \\
\text { 4th instar larvae stained with } \\
\text { AO; } 30 \text { min post-exposure }\end{array}$ & $\begin{array}{c}\text { Percent of guts from living } \\
\text { 4th instar larvae stained } \\
\text { with } \mathrm{AO} ; 30 \text { min post-exposure }\end{array}$ & $\begin{array}{c}\mathrm{LT}_{50} \\
\text { 2rd instar } \\
\text { larvae } \\
\text { (min) }\end{array}$ \\
\hline 15.7 & 25 & - & - & - \\
\hline 7.7 & 25 & $100(n=10)$ & All dead & 15 \\
\hline 3.8 & 40 & $100(n=9)$ & $56(n=9)$ & - \\
\hline 0.96 & 110 & - & - & 25 \\
\hline 0.77 & 120 & none dead & $20(n=15)$ & - \\
\hline 0.24 & - & - & - & 40 \\
\hline 7.7+gluNAc & 65 & - & - & - \\
\hline $7.7+$ mannose & 25 & - & - & - \\
\hline
\end{tabular}

Groups of five larvae were exposed to concentrations of prototoxin indicated in the Table. At various time intervals, the number of dead and living larvae was determined and the guts from dead living larvae were dissected and $\mathrm{AO}$ stained. From a minimum of five time points, in duplicate experiments, the time required to kill $50 \%$ of the larvae $\left(\mathrm{LT}_{50}\right)$ was determined
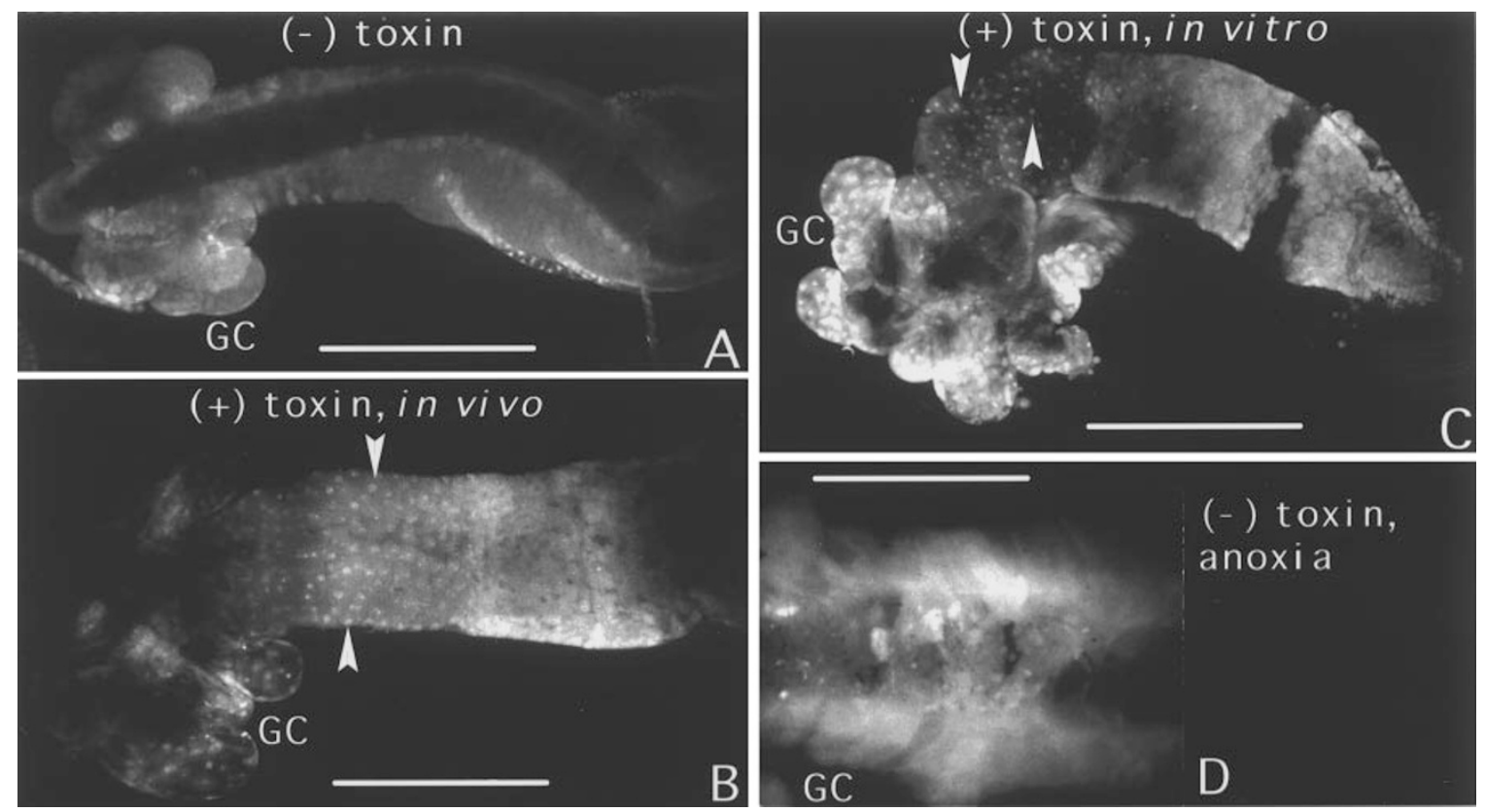

Figure 5 Acridine orange staining of larval midgut polytene nuclei. AO stained midgut isolated from late third-early fourth instar larvae not exposed to toxin (A). AO stained midgut from larvae exposed to $7.7 \mu \mathrm{g} / \mathrm{ml}$ toxin for $30 \mathrm{~min}$ prior to dissection (B). AO stained midgut treated with trypsin-digested toxin in vitro. As detailed in the Materials and Methods, guts from larvae not exposed to toxin were dissected and exposed to $14 \mu \mathrm{g} / \mathrm{ml}$ trypsin-digested toxin for $30 \mathrm{~min}$ and then stained with $\mathrm{AO}(\mathbf{C})$. AO stained anterior midgut from larvae killed by anoxia (D). Note there are no discrete, fluorescent polytene nuclei in panel $\mathbf{D}$ indicating the absence of programmed cell death. The anterior region of the midguts is indicated by the presence of the large bulbous gastric caeca (GC). The arrows indicate the fluorescent, AO stained polytene nuclei of the anterior midguts. In panels A-C the scale bars indicate a length of $1 \mathrm{~mm}$. In panel $\mathbf{D}$ the scale bar indicates a length of $0.5 \mathrm{~mm}$. 
$\mathrm{AO}$ (Figure $5 \mathrm{C}$ ) as was observed in midguts from larvae exposed to toxin in vivo.

\section{AO staining is inhibited by amino sugars}

To further investigate the relationship between toxin exposure, AO staining of midgut polytene cells and larval death, the sugar $\mathrm{N}$-acetylglucosamine (gluNAc), which has been shown to inhibit toxin-induced larval lethality (Muthukumar and Nickerson, 1987), was tested for its ability to also inhibit AO staining. Table 1 shows that gluNAc increased the $\mathrm{LT}_{50}$ whereas alpha methyl mannose did not. To determine if gluNAc affected toxin uptake or metabolism, larvae were treated with b-prototoxin alone, or b-prototoxin and gluNAc, or b-prototoxin and mannose. Guts were subsequently dissected, the proteins solubilized and subjected to Western blots (Figure 4B and C). Western blots of proteins from intact guts (Figure 4B, containing endoperitrophic material, ectoperitrophic material and gut epithelium) indicate that in the presence of gluNAc, ingestion of b-prototoxin occurred but that proteolytic cleavage may have been altered. More significantly, gluNAc appears to affect the passage of toxin fragments from the endoperitrophic space into the ectoperitrophic space (Figure 4C) since, in the presence of gluNAc, very little of the biotinylated toxin fragments could be detected in the ectoperitrophic space. Mannose may also interfere with toxin transport but, at the concentrations of toxin used $(7.7 \mu \mathrm{g} /$ $\mathrm{ml}$ ), this reduction did not effect the $\mathrm{LT}_{50}$ or $\mathrm{AO}$ staining. GluNAc not only affects toxin transport and the time of larval death but also the onset of cell death since larvae exposed to both toxin and gluNAc showed no AO staining of midgut polytene nuclei $30 \mathrm{~min}$ after toxin exposure. At this time, midguts from larvae exposed to $7.7 \mu \mathrm{g} / \mathrm{ml}$ toxin alone showed intense AO staining. Thus programmed death of larval midgut polytene cells is dependent not only on toxin ingestion, but also on the proper processing and transport of toxin into the ectoperitrophic space.

\section{Discussion}

Our results show that the Bti $\delta$-endotoxin induces programmed cell death in larval midgut polytene cells of Culex pipiens and that this may be part of the insecticidal mechanism of the toxin. The changes in AO staining (Figure 1) and nuclear morphology (Figure 1), the fragmentation of DNA into nucleosomal ladders (Figure 2), and the TUNELlabeling of apoptotic nuclei (Figure 3 ) are all found in toxintreated larvae, and resemble the characteristics of programmed cell death of vertebrate cells. In addition to the programmed cell death induced by larval ingestion of prototoxin, cell death has been induced, in vitro, using isolated midguts treated with trypsin-digested toxin. Programmed cell death initiated in vitro has a concentration dependence and time course similar to death induced in vivo. The ability to perform experiments in vitro will permit a study of the molecular, biochemical, and cellular events of programmed cell death in an intact tissue, and to analyze more easily the effects of potential activators and inhibitors of programmed cell death in general, and of insecticides in particular.
Interestingly, toxin-induced cell death follows a novel bimodal distribution along the anterior-posterior axis of the midgut: regardless of larval instar or toxin concentration, programmed cell death is detected first in the anterior midgut cells and only later in cells of the posterior midgut. While cells of the posterior midgut eventually die, they never stain with $\mathrm{AO}$. The bimodal staining pattern does not seem to be related to the relative binding of toxin to the gut epithelia since Ravoahangimalala and Charles (1995) reported that the toxin binds preferentially to the gastric caeca and posterior midgut, and less so to cells of the anterior midgut.

The anterior-posterior progression of toxin induced cell death is unexpected but may reflect an underlying metamorphic program of larval gut cell death. During mosquito metamorphosis larval polytene midgut cells are removed and replaced by regenerative diploid cells that will eventually form the epithelium of the adult midgut. We have found that midgut polytene cells of mosquito larvae undergo programmed cell death during metamorphosis. As in the case of toxin induced cell death, the metamorphic cell death program is initiated in the anterior midgut and progresses to the posterior midgut cells. However, metamorphosis-induced cell death occurs over a period of several days, not hours as in the case of toxin-induced cell death, and does not generally result in the death of the organism. It is likely that metamorphosis-induced cell death is regulated by the interaction of pro-death genes such as ICE-like proteases or the recently identified Drosophila genes reaper, head involution defective and grim (White et al, 1994, 1996; Grether et al, 1995; Chen et al, 1996; Pronk et al, 1996) and the pro-life genes such as bcl-2 and the inhibitors of apoptosis (IAPs) that have been described in mammalian and insect systems (Hay et al, 1995; Duckett et al, 1996). The $\delta$-endotoxin may induce a predetermined metamorphic pathway of gut cell death and modulate the timing of the cell death events. However it is unlikely that toxin-induced cell death per se causes the death of the larvae since metamorphosis-induced cell death does not. Rather, the inappropriate, accelerated cell death induced by toxin possibly causes larval death by altering epithelial cell physiology or, secondarily, by releasing substances from dying epithelial cells that cause programmed cell death, or necrotic death, in other cells which will then kill the larvae.

$\delta$-Endotoxins are capable of forming pores in cell membranes (Knowles and Ellar, 1984; von Tersch et al, 1995). The relationship between pore formation and programmed cell death is unknown, but it is interesting that cytotoxic $T$ lymphocytes can also induce apoptosis by secreting perforins, proteins which form pores in target cell membranes (Berke, 1995). The protease granzymeB/ fragmentin-2 must be co-secreted by killer $\mathrm{T}$ cells to effectively initiate target cell death. Other proteases, including intracellular ones such as interleukin- $\beta$ converting enzyme (ICE) and its relatives, have recently been found to play important roles in apoptosis, perhaps by initiating a proteolytic signal transduction cascade (Martin and Green, 1995). Interestingly, a highly specific receptor for a lepidopteran specific B.t. $\delta$-endotoxin is the zinc metalloprotease, aminopeptidase $\mathrm{N}$, which is normally found on 
the apical, extracellular surface of insect midgut cells (Knight et al, 1994, 1995). Perforin alone induces lysis, but not apoptosis of target cells. Similarly, $\delta$ toxins induce insect cells in culture to undergo a colloidal-osmotic shock (Knowles and Ellar, 1984) resulting in lysis. It has not been reported if these cells undergo programmed cell death. There are, thus, intriguing parallels between cytotoxic $T$ cell action and $\delta$-endotoxin-induced lethality, suggesting that potentially highly conserved mechanisms are at work in both examples.

Mosquitoes continue to be significant vectors for human diseases, and intense efforts to control mosquitoes have resulted in the selection for strains resistant to a wide variety of chemical and biological pesticides (McGaughey and Whalon, 1992). Our data indicates that programmed cell death may play a significant role in the activity of an important class of biological pesticides and suggests that other pesticides could be developed that specifically induce programmed cell death in insects.

\section{Materials and Methods}

\section{Toxin purification and biotinylation}

The $150 \mathrm{kDa} \delta$-endotoxin was isolated from spore-crystal preparations of $B$. thuringiensis subsp. israelensis strain HD522. Spore-crystal preparations were suspended in $10 \mathrm{mM}$ EDTA, homogenized by sonication and adjusted to $\mathrm{pH} 10.0$ by the addition of $\mathrm{NaOH}$ to solubilize the cytolytic toxin and other low molecular weight proteins. The particulate material was collected by centrifugation and the alkali extraction repeated until no further protein was detected in the supernatant fractions. The $150 \mathrm{kDa} \delta$-endotoxin in the resulting pellet fraction was solubilized by incubation of the resuspended pellet for $2 \mathrm{~h}$ at $4{ }^{\circ} \mathrm{C}$ in $50 \mathrm{mM}$ dithiothrietol (DTT), $10 \mathrm{mM}$ EDTA, pH 8.0. The DTT solubilized $\delta$-endotoxin was biotinylated in borate buffer, $\mathrm{pH} 8.5$, for $24 \mathrm{~h}$ at $4{ }^{\circ} \mathrm{C}$, using 10 moles of NSH-biotin (BioRad) for every mole of $\delta$-endotoxin (Bayer and Wilchek, 1990). Biotinylated $\delta$-endotoxin was dialyzed against distilled water, precipitated with 50\% ammonium sulfate, and used as a particulate suspension in distilled water.

\section{Toxin treatment of mosquito larvae and dissection of larval guts}

Culex pipiens egg rafts were obtained from Carolina Biological Inc. Larvae were reared at 20 to $22^{\circ} \mathrm{C}$ on mosquito food (Carolina Biologicals). Just before toxin treatment, five larvae are placed into a one dram glass vial, washed with distilled water and suspended in $1.0 \mathrm{ml}$ distilled water. Unless otherwise noted, $1.0 \mathrm{ml}$ of water containing the desired concentration of biotinylated toxin is added to the larvae. Larval death is defined as the permanent cessation of larvae movement. When exposed to toxin, the larvae feed and eventually stop swimming and sink to the bottom of the container. They continue a twitching motion and eventually cease all movement, even when prodded with a needle.

Larvae were placed into Mitsuhashi and Maramonosch insect medium (MMIM) from Sigma Chem. Co., and the guts were dissected and placed into the fresh medium. To remove the peritrophic membrane, the hindgut was cut and the peritrophic membrane pulled out.

\section{In vitro incubation of larval guts with trypsin digested toxin}

Biotinylated prototoxin was incubated for $2 \mathrm{~h}$ at room temperature with agarose-bound trypsin (Pierce), the trypsin removed by centrifugation and the proteolytic digest analyzed by PAGE which showed no prototoxin remained and that more than $50 \%$ of the resulting polypeptides had relative molecular masses of approximately $35-$ $50 \mathrm{kDa}$.

Larvae were dissected as above in MMIM and placed into fresh medium. An opening was made at the posterior midgut-hindgut junction and the peritrophic membrane removed. In the absence of toxin the guts twitched and contracted for up to $2 \mathrm{~h}$ after removal of the peritrophic membrane. In vitro toxin treatment was affected by adding trypsin digested toxin to the dissected guts and then removing the peritrophic membrane as described above.

\section{Acridine orange and bisbenzimide staining of midgut cells}

Larval guts were dissected and placed into fresh MMIM. Acridine orange (Sigma) was added to a final concentration of $1 \mu \mathrm{g} / \mathrm{ml}$ and stained for $3 \mathrm{~min}$. The stained midguts were rinsed twice with insect culture medium and observed using fluorescence microscopy. Increasing the time of staining did not increase the nuclear fluorescence but did greatly increase the amount of background cytoplasmic staining. It should be noted that the malpighian cells stained with acridine orange under all larval treatments.

For bisbenzimide (Sigma; Hoechst No. 33258) staining, the guts were first fixed for $45 \mathrm{~min}$ in phosphate buffered saline containing $4 \%$ paraformaldehyde. The larvae were then washed three times in phosphate buffered saline and bisbenzimide added to a final concentration of $1 \mu \mathrm{g} / \mathrm{ml}$. After $3 \mathrm{~min}$ in the stain, the guts were washed once in PBS and mounted for microscopy.

\section{Carbohydrate treatment of larvae}

Prior to treatment, five larvae were placed into a one dram glass vial and washed with distilled water. Solutions of Nacetyl glucosamine or alpha methyl mannose were added to give a final concentration of $0.18 \mathrm{M}$. The larvae appeared to swim and feed normally under these conditions. One hour after the addition of the sugars, the toxin was added.

\section{Gel electrophoresis}

Western blotting of toxin ingested by mosquito larvae was performed as follows. Larval guts are dissected and then placed in $50 \mu \mathrm{l}$ of $2 \times$ SDS-PAGE sample buffer and heated to $100^{\circ} \mathrm{C}$ for $2 \mathrm{~min}$. Twenty microliter samples were run on $7.5 \%$ acrylaide gels (FMC). After SDS-PAGE, the samples were electroblotted onto nitrocellulose filters. The biotinylated toxin was detected with alkaline phosphatase conjugated avidin. In some situations the peritrophic membrane was removed from the gut prior to solubilization in SDS-PAGE sample buffer.

Agarose gels electrophoresis of DNA from gut cells was performed as follows. Guts from control and toxin treated larvae were dissected and placed in $100 \mathrm{mM}$ Glucose, $50 \mathrm{mM}$ Tris (pH 7.6), $10 \mathrm{mM}$ EDTA (GTE) buffer. The GTE buffer was replaced with $50 \mathrm{mM}$ Tris, $10 \mathrm{mM}$ EDTA (TE), the gut cells lysed by the addition of SDS and the DNA was purified by phenol extraction and ethanol precipitation. The purified DNA was run on $2 \%$ agarose gels, stained with ethidium bromide and photographed. 


\section{In situ TUNEL labeling of larval gut cells}

For in situ TUNEL labeling, guts were dissected and then placed in phosphate buffered $4 \%$ paraformaldehyde for $45 \mathrm{~min}$ at room temperature. After fixation, the guts were washed in $100 \%$ Methanol, $95 \%$ Ethanol and finally 100\% Ethanol and subsequently frozen at $-70^{\circ} \mathrm{C}$ in Ethanol until stained. Prior to TUNEL labeling the guts were washed six times with phosphate buffered saline containing $0.1 \%$ Tween 20 (PBST). TUNEL labeling was carried out with the reagents and procedures supplied with the ONCOR TUNEL labeling kit, except the amount of Terminal deoxyribosyl transferase was reduced by 10 fold. The terminal transferase reaction was carried out for $3 \mathrm{~h}$ at $37^{\circ} \mathrm{C}$. The TUNEL labeled guts were washed with PBST for $1 \mathrm{~h}$ and then with the same buffer plus $4 \%$ bovine serum albumin for $30 \mathrm{~min}$. Antidigoxygenin (Boehringer Mannheim) antibody (diluted 1:800) was added and the guts incubated overnight at $4^{\circ} \mathrm{C}$ in PBST. After overnight incubation the guts were washed four times with PBST and twice with $100 \mathrm{mM}$ Tris (pH 9.5), $100 \mathrm{mM} \mathrm{NaCl}$ and $10 \mathrm{mM} \mathrm{MgCl}_{2}$. The alkaline phosphatase substrate was then added and color development monitored under a dissecting microscope.

\section{Preparation of figures}

Black and white photographic prints were made and the images digitized with a flatbed scanner. Image composites were made using Adobe Photoshop.

\section{Acknowledgements}

This work was partially supported by grants from FRAP-CUNY to JTN and DTS and a Howard Hughes Medical Institute grant to Brooklyn College.

\section{References}

Abrams JM, White K, Fessler Ll and Steller H (1993) Programmed cell death during Drosophila embryogenesis. Development 177: 29-43

Bayer EA and Wilchek M (1990) Protein biotinylation. Meth. Enzymol. 184: 138-159 Berke G (1995) The CTL's kiss of death. Cell 81: 9-12

Charles j-F and de Barjac $\mathrm{H}$ (1983) Action des cristaux de Bacillus thuringiensis var. israelensis sur l'intes moyen des larves de Aedes aegypti L., en microscope electronique. Ann. Microbiol. Inst. Pasteur 134A: 197-218

Chen P, Nordstrom W, Gish B and Abrams JM (1996) grim, a novel cell death gene in Drosophila. Genes Dev. 10: 1773-1782

Clements AN (1992) The Biology of Mosquitoes: development, nutrition and reproduction. (London: Chapman and Hall)

Curtiss A, Alcantara E, Dean DH and Chen XJ (1995) Mutations in domain I of Bacillus thuringiensis delta-endotoxin Cryl $A b$ reduce the irreversible binding of toxin to Manduca sexta brush border membrane vesicles. J. Biol. Chem. 270: 64126419

Duckett CS, Nava VE, Gedrich RW, Clem RJ, Van Dongen JL, Gilfillan MC, Shiels H, Hardwick JM and Thompson CB (1996) A conserved family of cellular genes related to the baculovirus iap gene and encoding apoptosis inhibitors. EMBO J. 15: $2685-2694$

de Barjac H (1978) Etude cytologique de l'action de Bacillus thuringiensis var israelensis sur larves de Moustiques. C.R. Acad. Sc. 286 Serie D: 1629-1632

Eastman A (1995) Assay for DNA fragmentation, endonucleases, and intracellular $\mathrm{pH}$ and $\mathrm{Ca}^{2+}$ associated with apoptosis. In Methods in Cell Biology, vol 46, LM Schwartz and BA Osborne, eds. (San Diego: Academic Press) pp. 41-56

Ellis RE, Yuan JY and Hortitz HR (1991) Mechanisms and functions of cell death. Annu. Rev. Cell Biol. 7: 663-698

Ferré J, Real MD, van Rie J, Jansens S and Peferoen M (1991) Resistance to the Bacillus thuringiensis bioinsecticide in a field population of Plutella xylostella is due to a change in a midgut membrane receptor. Proc. Natl. Acad. Sci. USA 88: $5119-5123$
Gill SS, Cowles EA and Francis V (1995) Identification, Isolation, and Cloning of a Bacillus thuringiensis CrylAc Toxin-binding Protein from the Midgut of the Lepidopteran Insect Heliothis virescens. J. Biol. Chem. 270: 27277-27282

Gill SS, Cowles EA and Paietrantinio PV (1992) The mode of action of Bacillus thuringiensis endotoxins. Annu. Rev. Entomol. 47: 615-636

Gravrieli Y, Sherman Y and Ben-Sasson SA (1992) Identification of programmed cell death in situ via specific labeling of nuclear DNA fragmentation. J. Cell Biol. 119: 493-501

Grether ME, Abrams JM, Agapite J, White Kand Steller H (1995) The head involution defective gene of Drosophila melanogaster functions in programmed cell death. Genes and Dev. 9: 1694-1708

Haider MZ, Knowles BH and Ellar DJ (1986) Specificity of Bacillus thuringiensis var. colmeri insecticidal delta-endotoxin is determined by differential proteolytic processing of the protoxin by larval gut proteases. Eur. J. Biochem. 156: 531540

Hay BA, Wassarman DA and Rubin GM (1995) Drosophila homologs of baculovirus inhibitor of apoptosis proteins function to block cell death. Cell 83: $1253-1262$

Hofmann $\mathrm{C}$, Vanderbruggen $\mathrm{H}$, Höfte $\mathrm{H}$, van Rie J, Jansens $\mathrm{S}$ and Van Mellaert $\mathrm{H}$ (1988) Specificity of Bacillus thuringiensis delta-endotoxins is correlated with the presence of high-affinity binding sites in the brush border membrane of target insect midguts. Proc. Natl. Acad. Sci. 85: 7844-7848

Hofmann C, Luthy P, Hutter Rand Pliska V (1988) Binding of the delta endotoxin from Bacillus thuringiensis to brush-border membrane vesicles of the cabbage butterfly (Pieris brassicae). Eur. J. Biochem. 173: 85-91

Höfte H and Whitely HR (1989) Insecticidal crystal proteins of Bacillus thuringiensis. Microbiol. Rev. 53: 242-255

Knight PJ, Knowles BH and Ellar DJ (1995) Molecular cloning of an insect aminopeptidase $\mathrm{N}$ that serves as a receptor for Bacillus thuringiensis $\mathrm{Cryl} / \mathrm{A}(\mathrm{c})$ toxin. J. Biol. Chem. 270: 17765-17770

Knight PJ, Crickmore N and Ellar DJ (1994) The receptor for Bacillus thuringiensis $\mathrm{CrylA}(\mathrm{c})$ delta-endotoxin in the brush border membrane of the lepidopteran Manduca sexta is aminopeptidase N. Mol. Microbiol. 11: 429-436

Knowles BH and Ellar DJ (1984) Colloid-osmotic lysis is a general feature of the mechanism of action of Bacillus thuringiensis delta endotoxin with different specificities. Biochem. Biophys. ACTA 924: 509-518

Maclntosh SC, Stone TB, Jokers TRS and Fuchs RL (1991) Binding of Bacillus thuringiensis proteins to a laboratory-selected line of Heliothis virescens. Proc. Natl. Acad. Sci. 88: 8930-8933

Martin SJ and Green DR (1995) Protease activation during apoptosis: death by a thousand cuts. Cell 82: $349-352$

Masson L, Mazza A, Brousseau R and Tabashnik B (1995) Kinetics of Bacillus thuringiensis toxin binding with brushborder membrane vesicles from susceptible and resistant larvae of Plutella xylostella. J. Biol. Chem. 270: $11887-11896$

Masson L, Lu YU, Mazza A, Brousseau Rand Adang MJ (1995) The CrylA(c) receptor purified from Manduca sexta displays multiple specificities. J. Biol. Chem. 270: 20309-20315

McGaughey WH and Whalon ME (1992) Managing insect resistance to Bacillus thuringiensis toxins. Science 258: 1451-1455

Muthukuma RG and Nickerson KW (1987) The glycoprotein toxin of Bacillus thuringiensis ssp israelensis indicates a lectin-like receptor in the larval mosquito gut. Appl. Environ. Microbiol. 53: 2550-2655

O'Brien JF (1965) Development of the Muscular Network of the Midgut in the larval stages of the Mosquito, Ades Aegypti Linnaeus. New York Entomological Society LXXIII: 226-231

O'Brien JF (1966) Origin and structural function of the basal gells of the larval midgut in the mosquito, Aedes aegypti Linnaeus. New York Entomological Society LXXIV: $59-63$

Oppert B, Kramer KJ, Johnson DE, Maclntosh SC and McGaughey WH (1994) Altered protoxin activation by midgut enzymes from a thuringiensis resistant strain of Plodia interpunctella. Biochem. Biophys. Res. Commun. 198: 940-947

Pronk GJ, Ramer K, Amiri P and Williams LT (1996) Requirement of an ICE-like proteases for induction of apoptosis and ceramide generation by REAPER Science 271: 808-810

Raff MA (1992) Social controls on cell survival and cell death. Nature 356: 397-400 
Ravoahangimalala O and Charles J-F (1995) In vitro binding of Bacillus thuringiensis var. israelensis individual toxins to midgut cells of Anopheles gambiae larvae (Diptera: Culicidae). FEBS Letters 362: 111-115

Richins CA (1945) The development of the midgut in the larva of Aedes dorssalis Meigen. Annals Entomological Society of America XXXVIII: 314-320

Robinow S, Talbot WS, Hogness DS and Truman JW (1993) Programmed cell death in the Drosophila CNS is ecdysone-regulated and coupled with a specific ecdysone receptor isoform. Development 119: 1251-1259

Sacchi VF, Parenti P, Hanozet GM, Giordana B, Luthy P and Wolfersberger MG (1986) Bacillus thuringiensis toxin inhibits K+-gradient-dependent amino acid transport across the brush borer membrane of Pieris brassicae midgut cells. FEBS Lett. 204: 213-218

Sanchis V, Chaufaux J and Pauron D (1994) A comparison and analysis of the toxicity and receptor binding properties of Bacillus thuringiensis CrylC delta-endotoxin on Spodoptera littoralis and Bombyx mori. FEBS Lett. 353: 259-263

Schwartz LM, Kosz L and Kay BK (1990) Gene activation is required for developmentally programmed cell death. Proc. Natl. Acad. Sci. 87: 6594-6598

Steller H (1995) Mechanism and genes of cellular suicide. Science 267: 1445-1449

Tabashnik BE (1994) Evolution of resistance to Bacillus thuringiensis. Annu. Rev. Entomol. 39: 47-79

Thompson CB (1995) Apoptosis in the pathogenesis and treatment of disease. Science 267: 1456-1452

Vadlamudi RK, Weber E, Ji I, Ji TH and Bulla LAJ (1995) Cloning and expression of a receptor for an insecticidal toxin of Bacillus thuringiensis. J. Biol. Chem. 270: $5490-5494$ van Rie J, Jansens S, Höfte H, Degheele D and van Mellaert H (1989) Specificity of Bacillus thuringiensis delta-endotoxins. Importance of specific receptors on the brush border membrane of the mid-gut of target insects. Eur. J. Biochem. 186: $239-247$

van Rie J, McGaughey WH, Johnson DE, Barnett BD and van Mellaert H (1990) Mechanism of insect resistance to the microbial insecticide Bacillus thuringiensis. Science 247: $72-74$

Villa M, Hanozet GM, Tasca M, Giordana B and Parenti P (1995) Interaction of the insecticidal crystal protein CrylA from Bacillus thuringiensis with amino acid transport into brush border membranes from Bombyx mori larval midgut. J. Invertebr. Pathol. 65: 35-42

Von Tersch MA, Slatin SL, Kulesza CA and English LH (1994) Membranepermeabilizing activities of Bacillus thuringiensis coleopteran-active toxin CryllIB2 and CryllIB2 domain I peptide. Appl. Environ. Microbiol. 60:3711-3717

White K, Grether ME, Abrams JM, Young L, Farrell K and Steller H (1994) Genetic control of programmed cell death in Drosophila. Science 264: 677-683

White K, Tahaoglu E and Steller H (1996) Cell killing by the Drosophila gene reaper. Science 271: 805-807

Wyllie AH, Kerr JFR and Currie AR (1980) Cell death: the significance of apoptosis. Int. Rev. Cytol. 68: 251-306

Zakeri Z and Lockshin RA (1994) The Aging Clock. In (Pieraoli W, Regelson W, and Fabris N, Eds.), pp. 212-229 